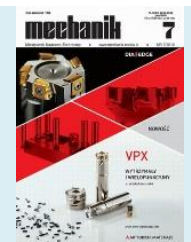

Authors: Jacek Stadnicki, Ireneusz Wróbel

Title of article: „Poprawa sztywności belki wzmocnienia tylnych drzwi samochodu osobowego” (“Improvement of passenger car rear side door beam stiffness")

Mechanik, Vol. 91, No. 7 (2018): pages 561-563

DOI: https://doi.org/10.17814/mechanik.2018.7.84

\title{
Improvement of passenger car rear side door beam stiffness
}

\author{
Poprawa sztywności belki wzmocnienia \\ tylnych drzwi samochodu osobowego
}

\section{JACEK STADNICKI IRENEUSZ WRÓBEL*}

To protect passengers against consequences of side crash side door beams are assembled to doors of passenger cars. Their stiffness is examined during stand tests. The FE model to simulate such a test is described. After verification the model has been applied to improve of rear door side beam stiffness.

KEYWORDS: FE modeling, nonlinear analysis of deformation, passenger car body, side door beam

To protect passengers against the effects of a side collision, reinforcements are installed in the doors of passenger cars - door beams that absorb part of the collision energy, deforming plastically. Fig. 1 shows the rear passenger car door after the crash test, with the visible beams of the door beam.

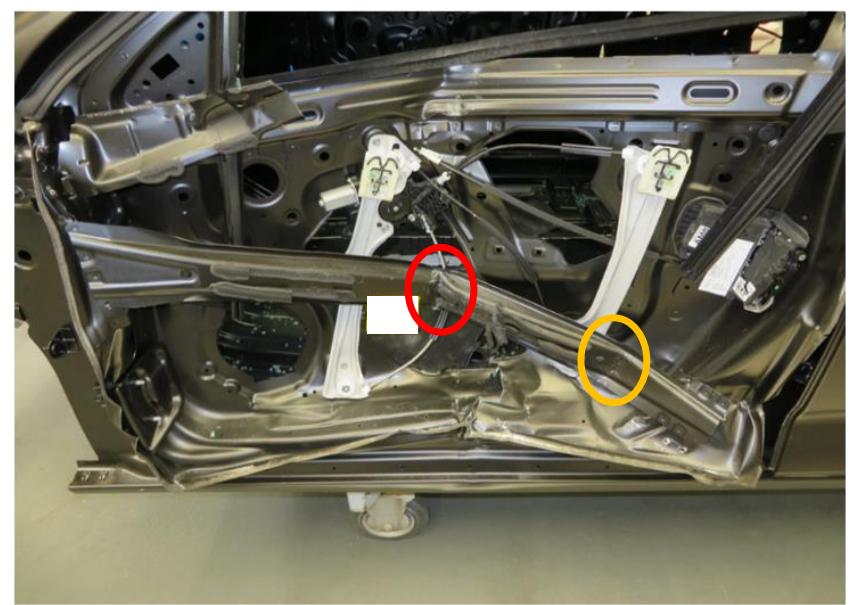

Fig. 1. Rear door beam after crash test

The experimental full-door crash test is the final verification of the correctness of the door-beam structure, therefore, at the stage of designing its construction and manufacturing technology, auxiliary test bench tests are carried out, the conditions of which are set by car manufacturers.

\footnotetext{
* Prof. dr hab. inż. Jacek Stadnicki (jstadnicki@ath.bielsko.pl), dr hab. inż. Ireneusz Wróbel prof. ATH (iwrobel@ath.bielsko.pl) Akademia Techniczno-Humanistyczna w Bielsku-Białej
}

Fig. 2 shows the diagram of the position used by General Motors [1]. The sliding supports for fixing the door beam are connected to the stand base by means of helical springs with a stiffness $k=250 \mathrm{~N} / \mathrm{mm}$, thus the susceptibility of the door frame is taken into account. A vertical displacement of the punch $f$ with a constant velocity $v<12.7 \mathrm{~mm} / \mathrm{s}(0.5 \% / \mathrm{s})$ to the ending value $f_{\mathrm{k}}=152.4 \mathrm{~mm}\left(6^{\prime \prime}\right)$ is applied. For the displacement $f_{\max }=115 \mathrm{~mm}$, the beam reaction force $F$ should be greater than the value $F\left(f_{\max }\right)=10 \mathrm{kN}$. Also the maximum force that the beam $\left(F_{\max }\right)$ and average force $\left(F_{\mathrm{av}}\right)$ can carry is calculated as the ratio of the area under the curve $F(f)$ to $t_{\mathrm{k}}$.

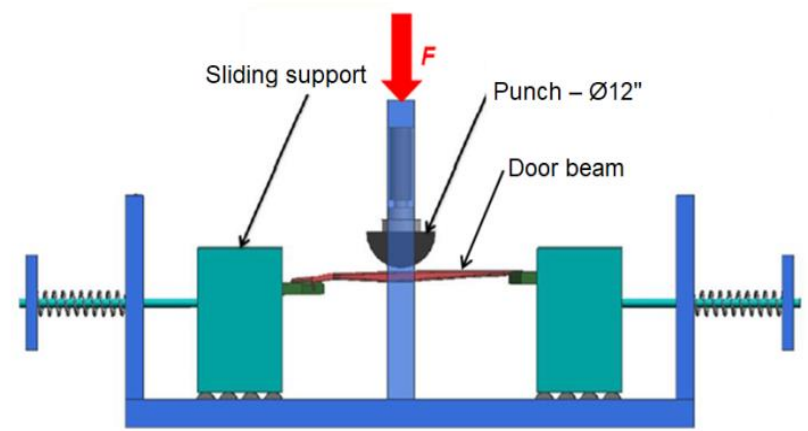

Fig. 2. Diagram of the door beam test station according to the requirements [1]

\section{Simulation of the door beam test}

To perform bench tests of a particular door beam, design and manufacture not only the beam itself, but also the die needed to fabricate it. The introduction of a construction change in the event of failure of the test entails the need to prepare a new die, which requires time and is expensive. For these reasons, a computational model of the door beam and the computer simulation station that reproduces the bench test was developed.

The analysis object was the door beam of the passenger car's rear door as shown in fig. 1, whose geometrical model is shown in fig. 3.

The door beam is made of sheet steel $1.4 \mathrm{~mm}$ thick, made of boron steel 22MnB5 with Al-Si layer (trade name: USIBOR1500). It is formed using hot forming technology, consisting of hot stamping and quenching in one operation. 


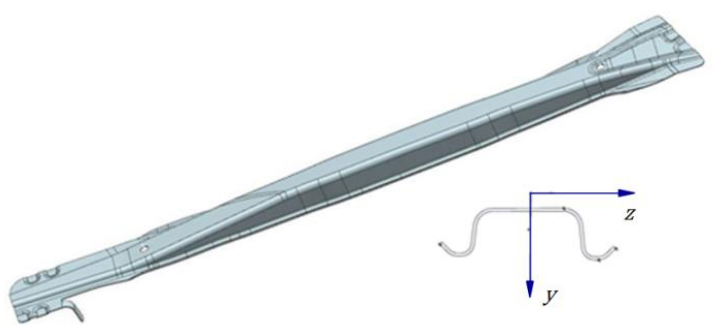

Fig. 3. Geometric model of the analyzed door beam

Fig. 4 shows the cross-sectional area of a beam after forming with a visible heterogeneous structure containing a martensite phase with fine perlite inclusions. Such a structure affects the mechanical properties of the beam material, which results in different values of the solid material model available in bi-tape FEM programs. In order to determine these constants, four flat test specimens were cut from the formed beam and subjected to a uniaxial tensile test in accordance with the requirements of ISO 6892-1: 2009 A224.

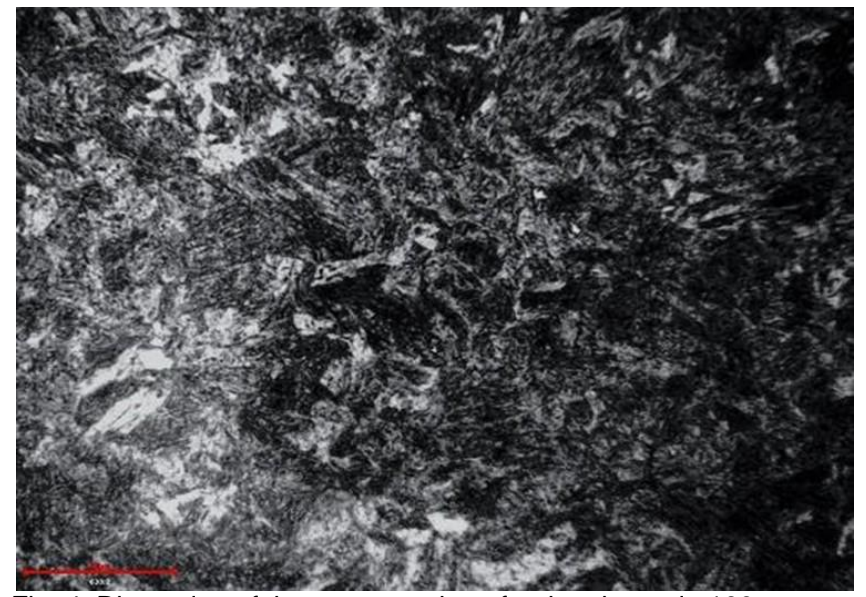

Fig. 4. Dimension of the cross-section of a door beam in 100x magnification

Due to the isotropy of material properties, the averaged characteristic $\sigma(\varepsilon)$ was developed, on the basis of which the conventional yield limit $R_{\mathrm{p} 0,2}=1173 \mathrm{MPa}$ and the strength limit $R_{\mathrm{m}}=1615 \mathrm{MPa}$ were determined. To describe the nonlinear behavior of the material in the field of plastic deformation, this part of the characterization of $\sigma\left(\varepsilon_{\mathrm{pl}}\right)$ has been approximated with the fourth degree polynomial.

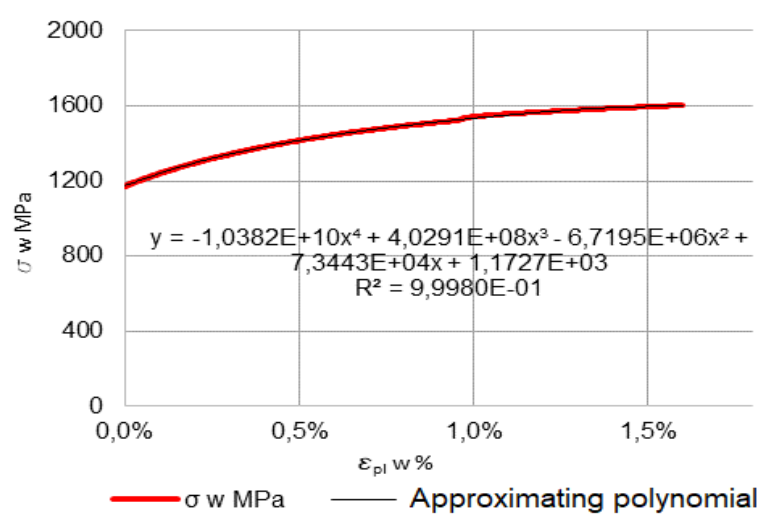

Fig. 5. Averaged plastic deformation characteristic and approximating polynomial

Fig. 5 shows both curves and the polynomial equation and the mutual correlation coefficient $R^{2}$.

Since the correlation of the approximate polynomial with the averaged characteristic $\sigma\left(\varepsilon_{\mathrm{pl}}\right)$ is very good, the law of hardening in the material model was defined by means of 10 points determined from the polynomial.

The simulation of the door bending test for the door beam was carried out in the LS Dyna program. The scheme of the FEM model is shown in fig. 6.

In the FEM model, four-node shell deformable elements were used, which for the beam were susceptible, and for the stamp and sliding supports - undeformable. The sliding supports were connected with the mainstay of spring elements with stiffness and initial tension in accordance with the test conditions [1]. The screw connection of the beam with supports was modeled with the help of equations of constraints, and the effect of the punch on the beam was represented by contact elements type surface-to-surface with friction. During the simulation, a linearly increasing vertical displacement of the punch was set at a speed of 2 $\mathrm{mm} / \mathrm{s}$ to the value of $152.4 \mathrm{~mm}\left(6^{\prime \prime}\right)$ [1].

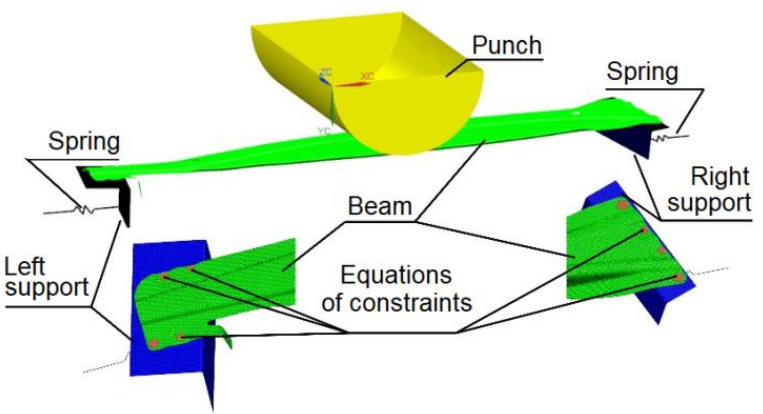

Fig. 6. Diagram of the FEM model of the position

In total, the FEM model of the station created 45001 finite elements connected in 45842 nodes, including the tested beam - 36881 elements connected in 37455 nodes.

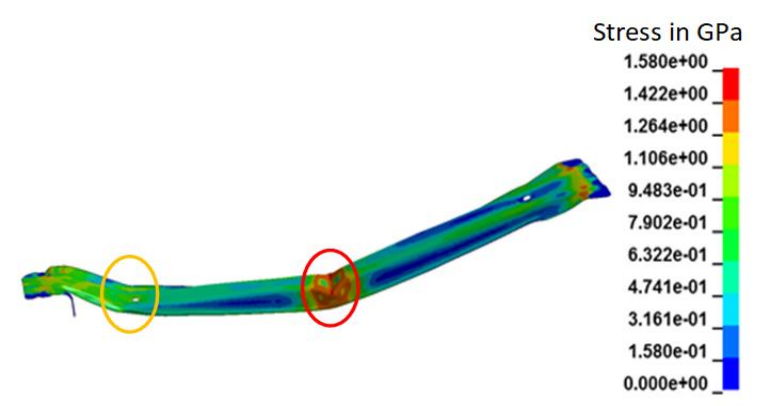

Fig. 7. Deformation and stress reduced in the door beam after simulation of a bench test

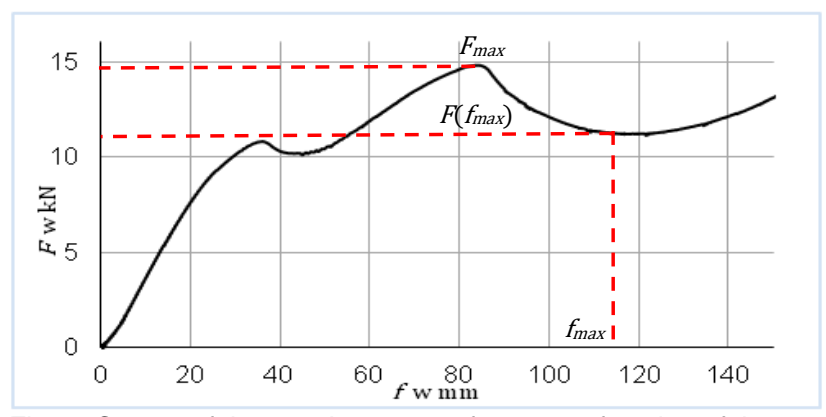

Fig. 8. Course of the punch pressure force as a function of the deflection of the stem beam during simulation of a bench test

Fig. 7 shows the deformation of the beam and the stress reduced in the beam after simulation of the bench test. Fig. 8 illustrates the course of the punch pressure force as a function of the deflection of the beam under the punch during the test.

Comparison of simulation results of the bench test (fig. 7) with the image of door deformation after the side impact test (fig. 1) shows that: 
- test conditions of the test bench well reflect the side impact test,

- assumptions of the FEM model to simulate the position test were accepted correctly.

From the graph in fig. 8 it can be read that the stiffness of the analyzed beam is sufficient because for deflection $f_{\max }=$ $115 \mathrm{~mm}$, the force $F\left(f_{\max }\right)=11.26 \mathrm{kN}$, although the maximum force that can be loaded on the beam is $F_{\max }=14,86 \mathrm{kN}$, and the average force during the test $F_{\mathrm{av}}=11.54 \mathrm{kN}$.

\section{Improvement of the rigidity of the door beam}

In fig. 7 , it can be noticed that when bending the door beam, two plastic joints are formed - the first is located approx. $100 \mathrm{~mm}$ from the left end and the second - half the length of the beam.

Observation of the simulation showed that the bending of the beam first occurs near the first one and then near the second plastic hinge. To explain this, changes have been made to the cross-section parameters along the length of the beam with the help of CATIA tools.

Fig. 9 shows changes in section $A$ and the main moment of inertia of the $I_{z z}$ section (fig. 3).

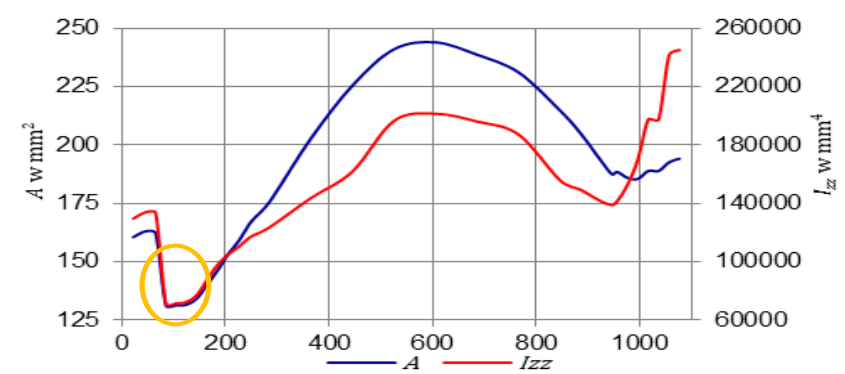

Fig. 9. Change of the section $A$ and the moment of inertia of the $I_{z z}$ cross-section along the length of the beam

In the diagram (fig. 9), one can find confirmation that in a place about $100 \mathrm{~mm}$ from the left end of the beam, additionally weakened by hole, there is a step drop in the stiffness of the beam. It is the reason for the creation of a plastic joint, which initiates the bending of the beam in this place, and then in the middle of its length.

The correct conclusion was that in order to stiffen the whole bar, its shape should be changed and the step change in stiffness should be eliminated in this place. Because it was not possible to remove the hole weakening the beam, the shape of the beam was changed here, using the available space determined by the beam assembling conditions in the door. For a beam with increased bending stiffness, a simulation of a bench test was performed again.

A comparison of the course of the pressure force of the punch $F$ as a function of deflection of the beam under the punch $f$ for the original beam and beam with increased stiffness is shown in fig. 10.

The analysis of fig. 10 and the course of deformation during the simulation of the bench test indicate that the effect was opposite to the intended one. The beam does not meet the requirements of the test, because for deflection $f_{\max }=115 \mathrm{~mm}$, the force $F\left(f_{\max }\right)<10 \mathrm{kN}$. The maximum force that can be loaded on the beam to $F_{\max }=13.27 \mathrm{kN}$ and the average force during the test to $F_{\mathrm{av}}=11.07 \mathrm{kN}$ also decreased.

Therefore, once again the shape of the beam has been changed by introducing an additional rib in the right part of the beam (the solution is the subject of a patent application), which is to initiate an additional plastic joint in the place where the beam was not tightened.

After many simulations of the test, the best shape and position of this embossing was determined, which is shown in fig. 11. A comparison of the corresponding pressure force of the $F(f)$ punch with the previous beam constructions is shown in fig. 10.

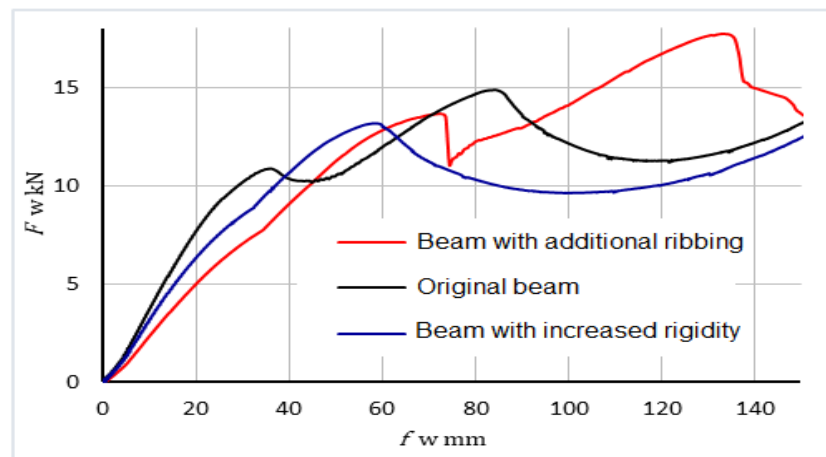

Fig. 10. Comparison of the punch pressure force as a function of deflection under the punch during the bench test for the original beam, the beam with increased stiffness and the beam with additional ribbing

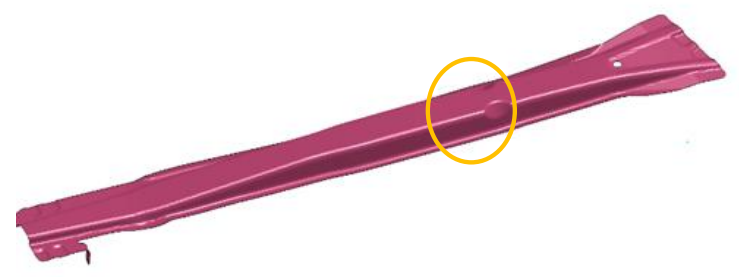

Fig. 11. Geometric model of the door beam with increased rigidity, with additional ribbing

The table presents the values of characteristic values for the door beams analyzed, which were determined based on the simulation of the bench test.

TABLE. Comparison of numerical values of characteristic values for the door beams analyzed

\begin{tabular}{|c|c|c|c|c|}
\hline Quantity & Unit & Original beam & $\begin{array}{c}\text { Beam with } \\
\text { increased } \\
\text { rigidity }\end{array}$ & $\begin{array}{c}\text { Beam with } \\
\text { additional } \\
\text { ribbing }\end{array}$ \\
\hline$F_{\max }$ & $\mathrm{kN}$ & 14.91 & 13.27 & 17.93 \\
\hline$F\left(f_{\max }\right)$ & $\mathrm{kN}$ & 11.35 & 9.82 & 16.22 \\
\hline$F_{\text {sr }}$ & $\mathrm{kN}$ & 11.54 & 11.07 & 12.34 \\
\hline
\end{tabular}

\section{Conclusions}

Bending test simulations of the door beam have shown that: - proposed FEM model of the position well-modeled the actual position test;

- because the course of the hot forming process affects the structure of the material, the material model should be designated for a specific process,

- conducting comparative analyzes of various beam structures at the design stage allowed to find the best beam form due to its stiffness and the ability to absorb collision energy,

- original beam construction with additional local weakening of the stiffness in the place defined by the constructor, which results in an additional local plastic joint, resulted in: improved beam stiffness (the highest force that the beam can carry during the test, $F_{\max }$ increased from $14,91 \mathrm{kN}$ to $17.93 \mathrm{kN}$, i.e. $20 \%$ ), better protection of passengers against collision damage (strength at the maximum deformation test $F\left(f_{\max }\right)$ allowed by the requirements increased from $11.35 \mathrm{kN}$ to $16.22 \mathrm{kN}$, i.e. by $43 \%$ ), increased collision energy absorption capacity (mean force during the $F_{\mathrm{av}}$ test increased from 11.54 $\mathrm{kN}$ to $12.34 \mathrm{kN}$, i.e. by $7 \%$ ).

\section{REFERENCES}

http://standards.globalspec.com/std/10053611/gmw16418GMW164 18 Door Beam Bending Strength Test, Worldwide Engineering Standards. 
Translation of scientific articles, their computer composition and publishing them on the website www.mechanik.media.pl

by original articles in Polish is a task financed from the funds

of the Ministry of Science and Higher Education designated for dissemination of science.

\section{Ministry of Science} and Higher Education

Republic of Poland 